\title{
A MICRO HYBRID WIND-PV BASED ON GRID ENERGY SYSTEM WITH ENHANCED EFFICIENCY
}

\author{
Mehmet Ali Özçelik ${ }^{* 1}$ \\ ${ }^{1}$ Gaziantep University/Vocational School of Technical Science/Department Electric and Energy, \\ Şehitkamil/Gaziantep/Turkey \\ *Corresponding author; ozcelik@gantep.edu.tr
}

\begin{abstract}
Wind and solar energy hold an important position in renewable energy sources. In wind energy conversion, the output power can change depending on the speed and intensity of the wind while in solar energy conversion it can change depending on the solar radiation and temperature. The energy conversion that combines these two energy types is called hybrid system. The energy produced by the wind and $P V$, hybrid power systems shows variance depending on the speed and intensity of wind and irradiation and temperature of $P V$ panels in some cases the wind power and the PV power may not be at the expected level for the on grid micro inverter. This study aims to increase energy sustainability on grid based the hybrid power systems. The hybrid power system's output voltage is constantly measured with a voltage sensor. The input voltage range of the micro-inverter has been tried to be kept at a value that can give energy to the grid. In order to achieve this, the energy continuity is increased by providing battery support at voltages close to the minimum power value that will enable micro-inverter conduction.
\end{abstract}

Key Words: PV energy conversion, Wind energy conversion, Hybrid system, on grid micro inverter, Smart system

\section{Introduction}

Studies on renewable energy sources such as wind and sun continue to hold popularity. [1]. The limited availability of fossil resources and the environmental pollution they cause make clean and sustainable renewable energy sources advantageous [2]-[3]. Among environmentally-friendly energy resources, wind and solar energies are at the forefront [4]. By the end of 2014, 89 countries had wind turbines, and 59 had PV panels installed, some of them being among emerging and developing economies (Figure 1) [5]. As seen in Fig.1, wind and solar energies hold a key role in global electric generation.

There are various researches on how to improve the efficiency and make the installation of wind and PV energy systems more cost-effective. In relevant research in the literature, to reach maximum power, several algorithms and controller such as SST $k-\omega$ turbulence model [6], improved differential evolution and bee algorithm [7]-[8], Piezoelectric energy harvester [9], adaptive neuro-fuzzy strategy [10] perturbation and observation $(\mathrm{P} \& \mathrm{O})$ [11], fuzzy logic, incremental conductance [12], current control loop [13], FPGA and DSP [14] controller etc. have been proposed and applied 


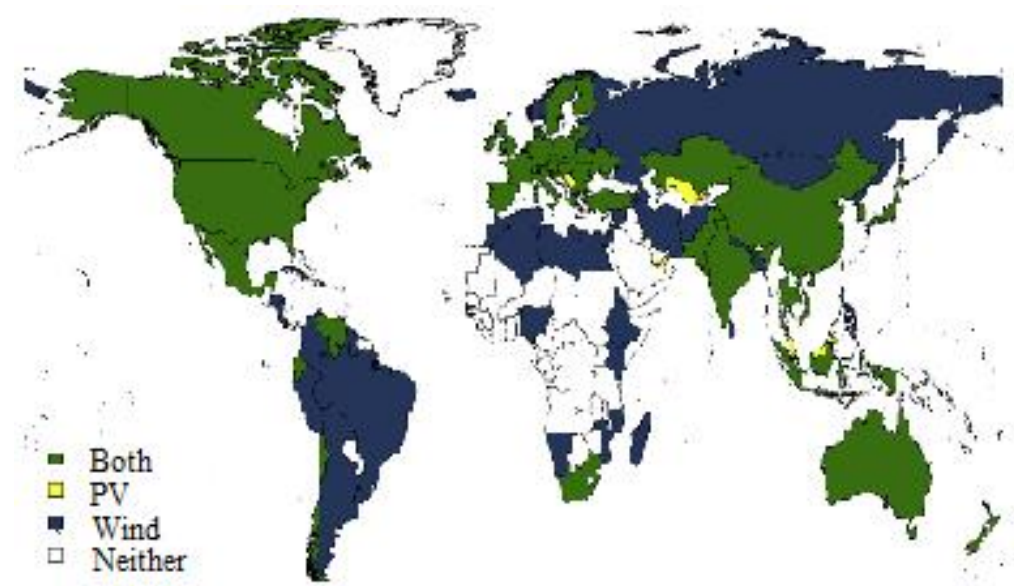

Figure 1. Global deployment of wind and PV, countries with any wind or PV installations.

There are various researches on how to improve the efficiency and make the installation of wind and PV energy systems more cost-effective. In relevant research in the literature, to reach maximum power, several algorithms and controller such as SST k- $\omega$ turbulence model [6], improved differential evolution and bee algorithm [7]-[8], Piezoelectric energy harvester [9], adaptive neuro-fuzzy strategy [10] perturbation and observation $(\mathrm{P} \& \mathrm{O})$ [11], fuzzy logic, incremental conductance [12], current control loop [13], FPGA and DSP [14] controller etc. have been proposed and applied.

The output power of a wind turbine and PV panel significantly varies depending on wind speed and solar irradiation/temperature respectively. So, every wind turbine and PV panel has a very unique power performance curve. The most relevant goals of PV/Wind hybrid energy systems include cost reduction of the power-converter stage, increased efficiency of wind turbines, PV panels and converters, and considerable improvement in converter/inverter reliability and in order to collect the maximum available power, the operating point needs to be tracked continuously using an algorithm.

Nowadays small-scaled energy generation systems are gaining popularity and they offer the facility to generate electricity at the place of consumption (on-site electricity generation). The popularity of these small-scaled energy generation systems has led to the creation of small and strong converters called micro-inverters [16]. Micro-inverters are module-based inverters that have sparked much interest recently and offers a host of advantages, such as low converter power rating, low power losses, accurate maximum power point tracking ability [17]. Thanks to these inverters, the electric energy obtained from the small, strong wind and PV energy systems can be directly transmitted to the grid. Moreover, the highest value of power from these micro-inverters can be accumulated in a single bus and supplied to the grid.

This study focuses on an optimization of micro on grid PV/Wind hybrid energy system, the output voltage of the wind/PV hybrid system, connected to the grid with micro-inverter, has been constantly measured at certain intervals. In case the measured values are below the maximum power, the input voltage interval, the DC (direct current) at the output of the hybrid regulator was increased by the battery and thus the power transfer to the grid was continued. In this way, more power is transmitted to the grid by making use of the power obtained from the hybrid system as well. 


\section{Material}

\subsection{PV Model}

The PV models are the type of systems that convert the radiation and heat they are exposed to directly into electric. The obtained electric is in the DC character and the most popular model used to represent the PV module is the current source in parallel with a diode, with a parallel and series resistor [18]. This is shown in Fig. 2 and the equation of the circuit in Fig.2 is given in equation (1).

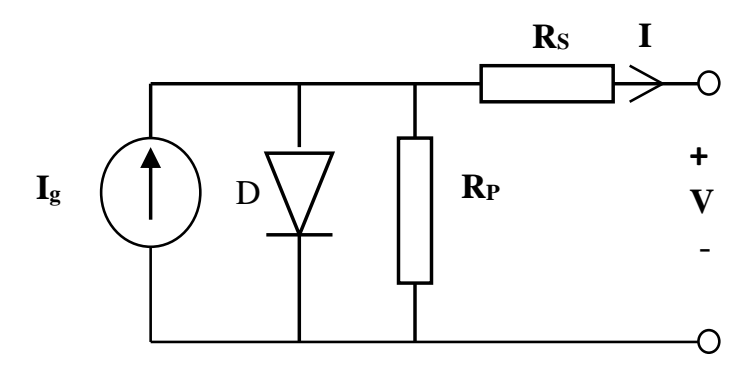

Figure 2. Equivalent circuit diagram for PV model

Solar cells have a current source that are connected with a parallel diode and resistance, to which a serial resistance is connected.

$$
I=I_{g}-I_{S}\left(e^{\frac{v+i R_{S}}{a}}-1\right)-\frac{V+i R_{S}}{R_{P}}
$$

In the equation above, $I$ is the PV current, $V$ is the PV voltage, $R_{s}$ is the series resistor, $R_{p}$ is the parallel resistor, $I_{g}$ is the light-generated current, $I_{s}$ is the diode's saturation current, and a $=\mathrm{AkT} / \mathrm{q}$, where $\mathrm{A}$ is the diode ideality factor, $\mathrm{k}$ is Boltzmann's constant, $\mathrm{T}$ is the temperature, and $\mathrm{q}$ is the charge of an electron.

\subsection{Wind Model}

Wind turbines are the most important elements of wind energy conversion systems; first they convert the wind-like moving air into mechanical energy and then to the electrical energy. As shown in Fig. 3 Wind turbines can be categorized as those with vertical axis and those with horizontal axis. Vertical axis turbines operate in all directions of the wind while horizontal axis turbines can operate in both wind direction and against the direction of the wind (upwind).

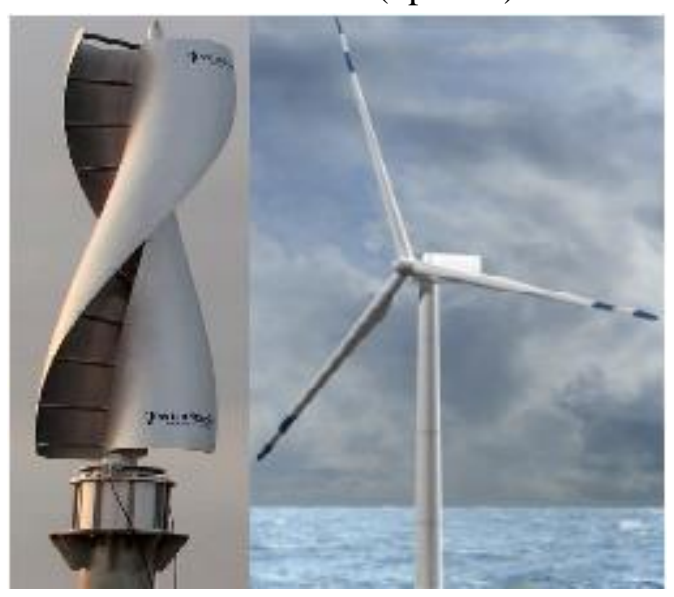

(a)

(b)

Figure 3. Vertical axis (a) Horizontal axis (b) wind turbines 
The power that can be obtained from a wind at V speed is correlated with the mass flow passing through the circular sweeping area that the turbine sweeps. While the diameter of the turbine wing is noted as (D), the radius is $(r=D / 2)$. By using the are of the circle $\left(\pi r^{2}\right)$, we can find the area (A, $\left.\mathrm{m}^{2}\right)$ swept by the wing as shown in equation 2 [19]. $\rho\left(\mathrm{kg} / \mathrm{m}^{3}\right)$ being the air density, the wind power (P) related with the mass flow can be calculated by equation 3 from $\mathrm{m}=\rho \mathrm{AV}$.

$$
\begin{aligned}
& A=\frac{\pi}{4} D^{2} \\
& P=\frac{1}{2} \rho A V^{3}
\end{aligned}
$$

\subsection{PV/Wind Hybrid Energy Conversion}

Figure 4 shows the PV/Wind hybrid energy conversion system connected to the grid; where the DC / DC converter regulates the DC from the PV panel output and gives it to the DC bus, the AC / DC converter converts the AC from the wind turbine output to DC. The charge regulator supplies the DC that charges the battery. By the on-grid inverter the DC power from the DC bus output is converted to AC power and transferred to the grid. On-grid and micro-inverters are examples of DC / AC converters used in these systems.

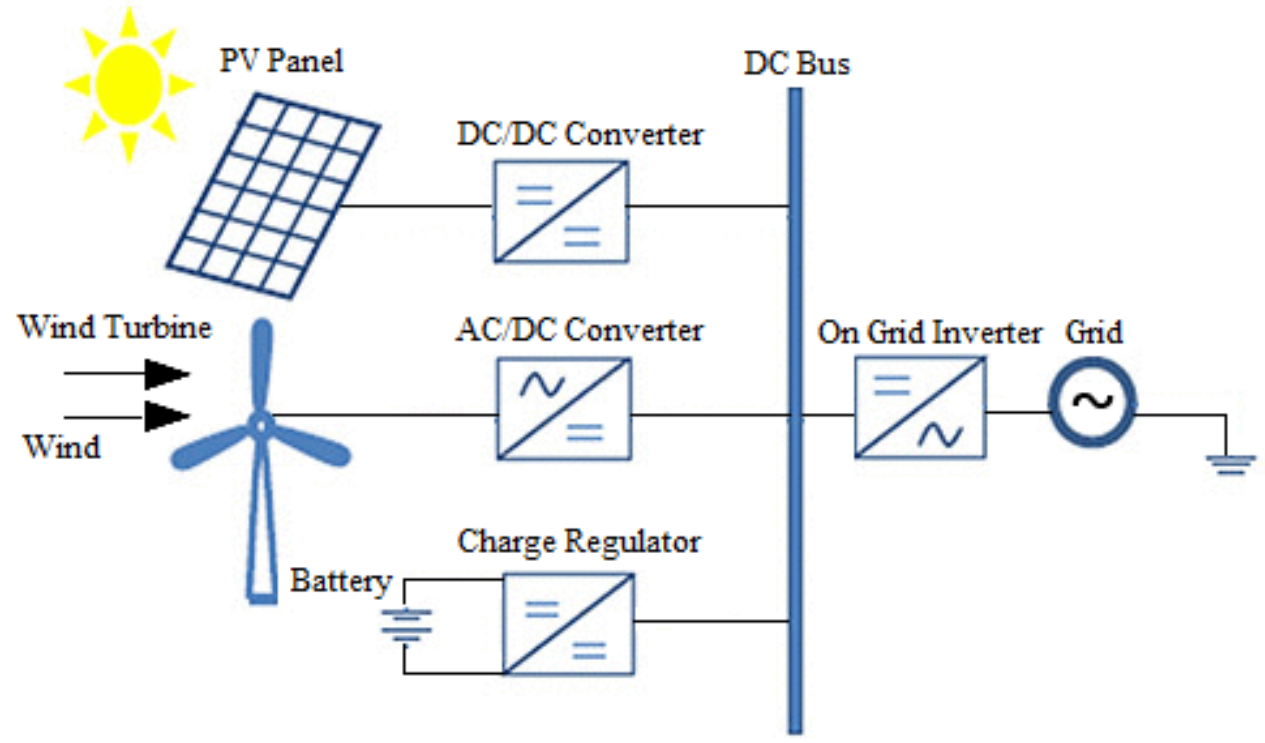

Figure 4. PV/Wind Hybrid energy conversion

\section{Method}

\subsection{The Proposed Algorithm of the PV/Wind Hybrid System}

The full power voltage range of the micro-inverter's DC input used in the on-grid system is 30$50 \mathrm{~V}$. In the proposed algorithm, the full power minimum value of $30 \mathrm{~V}\left(\mathrm{~V}_{\mathrm{MVR}}\right)$ of the inverter is taken as the reference value. The battery voltage used in the supply of DC loads in the system is called

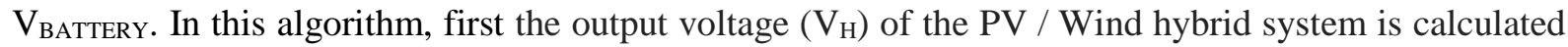
by voltage divider resistors and this calculated value is given to the $A_{1}$ analog input of the Arduino Mega Card. Then, if the measured $V_{H}$ value is above $V_{\text {MVR- }} V_{\text {BATTERY }}$ difference and below the $V_{M V R}$ 
value, the digital output pin of the Arduino mega board active mode (1) is serial connected to the DC generator hybrid system output and thus the input voltage of micro-inverter is increased. This way, the energy transmission of the on-grid micro-inverter to the grid is continued. When the hybrid system output voltage value rises above the $\mathrm{V}_{\mathrm{MVR}}$, the battery is disabled with the $\mathrm{D}_{1}$ pin being passive mode (0). This way, by the iverter's being active, the low powers at the output of the hybrid system can be made use of as well. The flowchart of the proposed algorithm is provided in Fig.5.

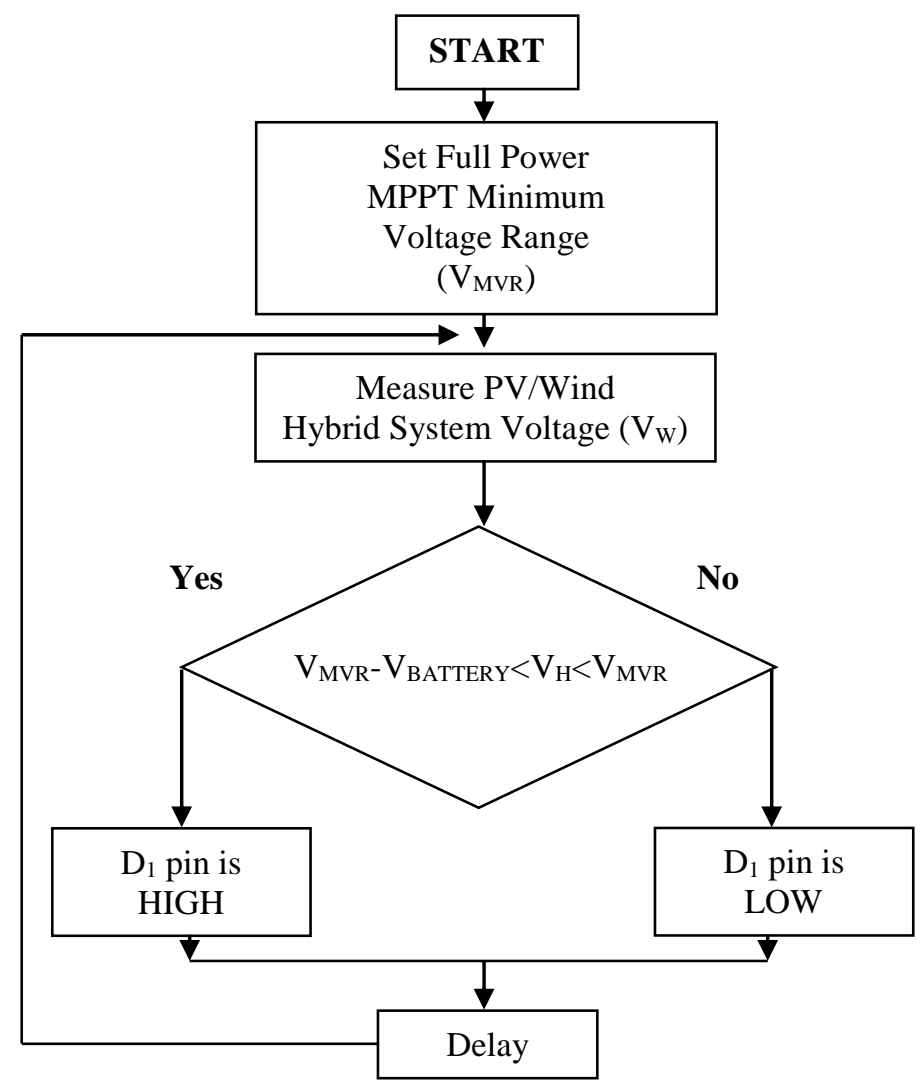

Figure 5. Proposed algorithm

\subsection{Experimental Setup}

The Experimental setup is seen in Fig.6. The Universal motor shaft is coupled with 500 Watt AC 24 wind turbine. With the speed regulator, the Universal motor is adjusted and in line with the speed, 3-phase alternative voltage is obtained. The $100 \mathrm{~W}$ PV panel is installed on the roof; depending on the radiation and temperature, DC is obtained from the PV panel output. The 3-phase turbine output and PV panel outputs have been given to the hybrid control card input, the DC from the hybrid control card output is given to the on-grid micro-inverter's input. The micro-inverter is $600 \mathrm{~W}$ and the $\mathrm{V}_{\mathrm{DC}}$ full power voltage range is $30-50 \mathrm{~V}$. There have been used as battery voltage, $12 \mathrm{~V}$, as DC load, $10 \mathrm{~W}$ LED lamp, as a control card, Arduino Mega and for DC and battery, a charge regulator. 


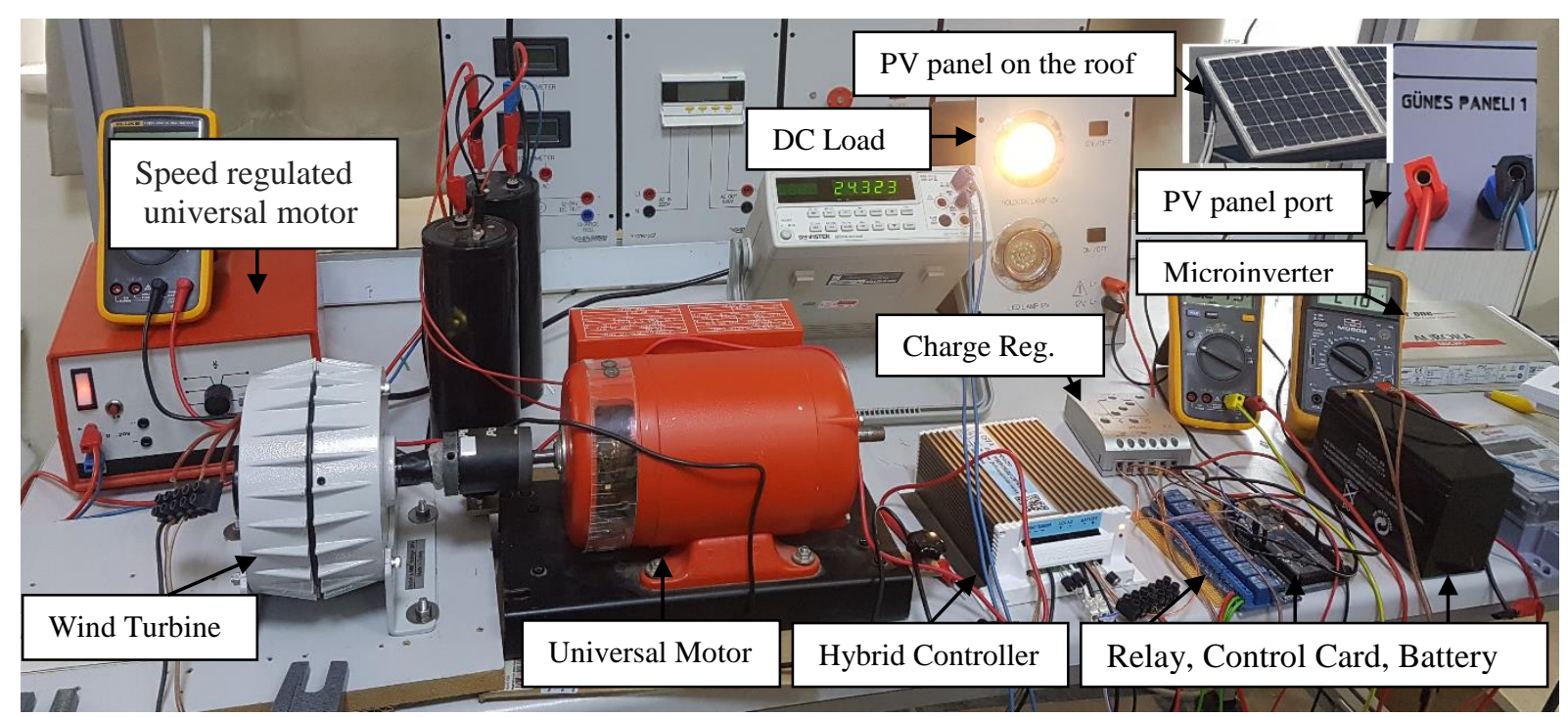

Figure 6. The proposed PV/Wind hybrid system experimental setup

The block chart of the experimental setup is given in Figure 7. The 600 Watt inverter is connected directly to the grid. The $10 \mathrm{~W}$ LED lamp is supplied with the charge regulator and the battery. The working of the proposed system is as follows.

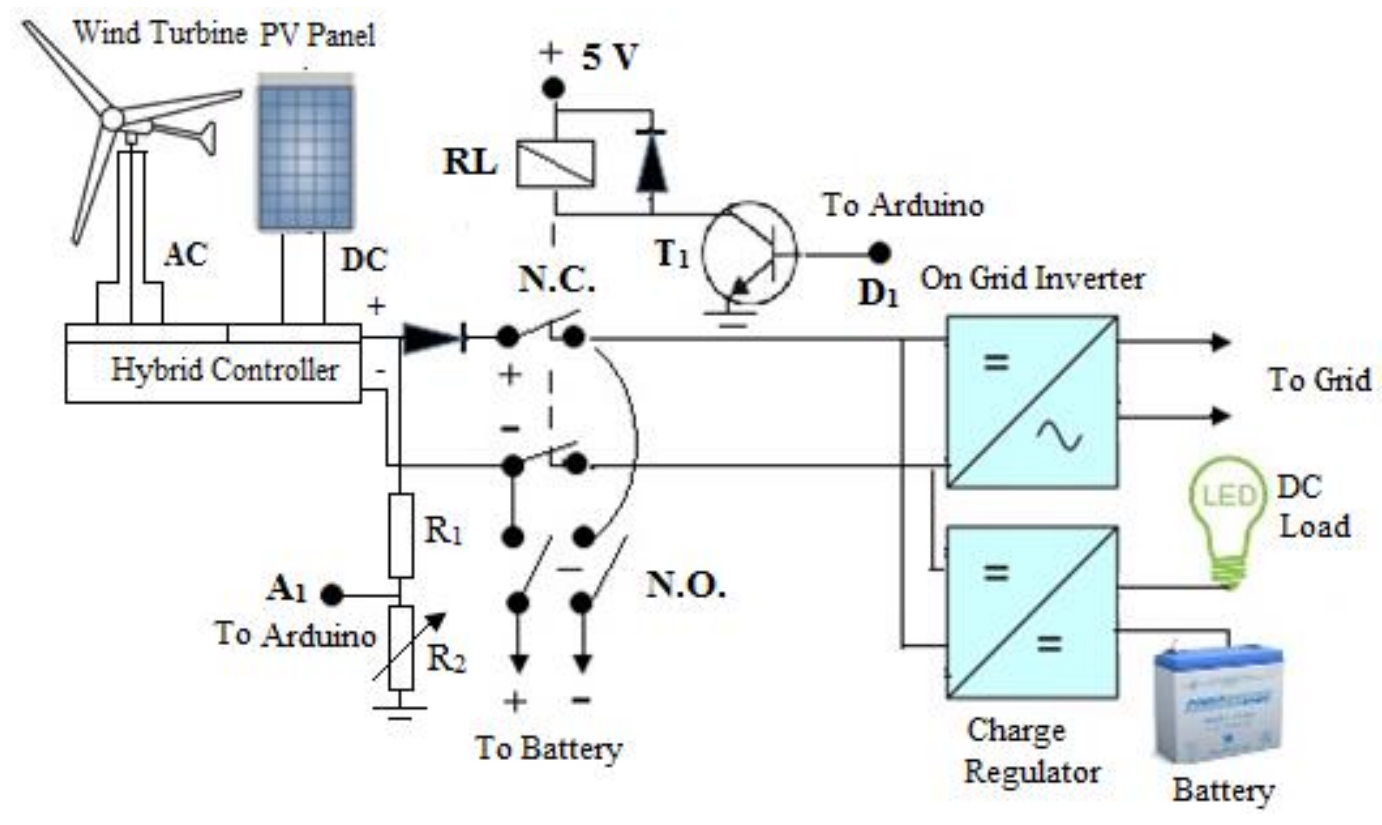

Figure 7. Wind/PV hybrid based smart on grid system block chart

- The DC voltage obtained from the Wind / PV hybrid circuit is given to the A1 analog input of the Arduino mega board via R1 and R2 voltage divider resistors. The voltage obtained from the turbine cycle is proportional to the speed in table 1 and as shown in Figure 8. 
Table 1. Wind Turbine Speed and Output Voltage

\begin{tabular}{|c|c|}
\hline Speed (RPM) & Output voltage(V) \\
\hline 205 & 3.53 \\
\hline 253 & 3.75 \\
\hline 265 & 5.84 \\
\hline 352 & 7.8 \\
\hline 422 & 9.5 \\
\hline 478 & 10.73 \\
\hline 544 & 12.20 \\
\hline 603 & 13.45 \\
\hline 679 & 15.29 \\
\hline 725 & 16.23 \\
\hline 770 & 17.07 \\
\hline 800 & 17.90 \\
\hline 892 & 19.85 \\
\hline 920 & 20.53 \\
\hline 987 & 22.10 \\
\hline 1100 & 24.9 \\
\hline & \\
\hline
\end{tabular}

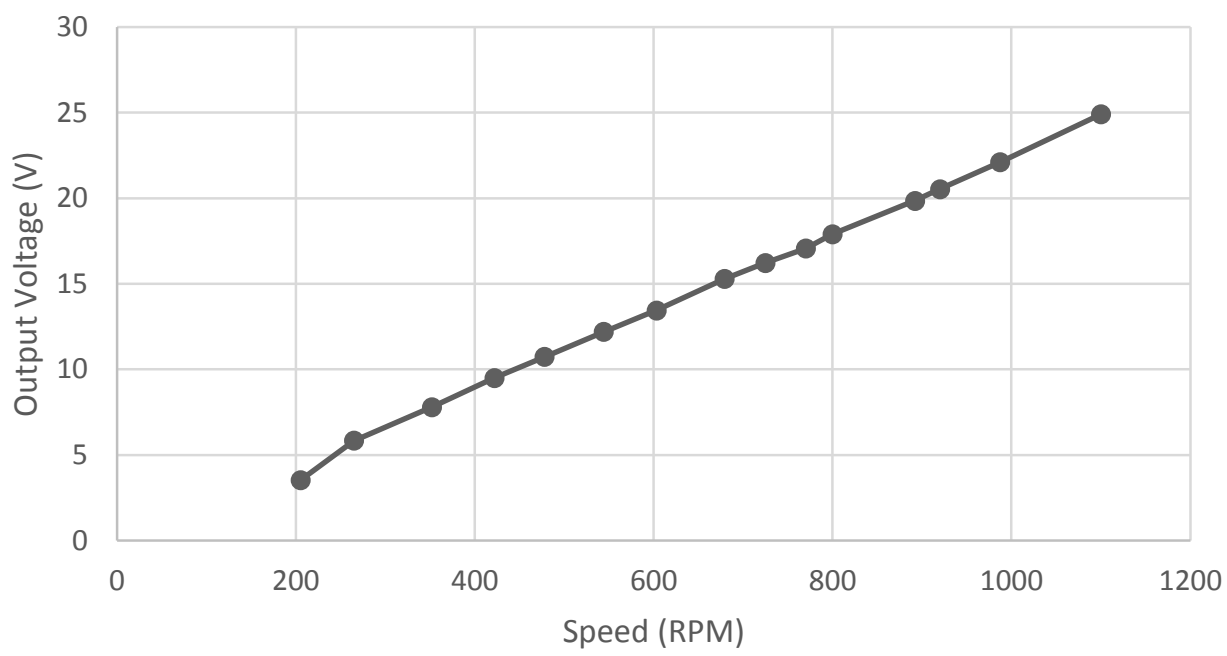

Figure 8. Speed and output voltage of wind turbine

- If the DC received from PV/Wind hybrid circuit is enough, the inverter will give energy to the grid. If it is above the $\mathrm{V}_{\mathrm{MVR}}-\mathrm{V}_{\text {BATTERY }}$ difference and below $\mathrm{V}_{\mathrm{MVR}}$ value, the $\mathrm{D}_{1}$ pin of the control card will activate the $T_{1}$ transistor conduction. Figure 9 shows the voltage range in which transistor 1 or 0 (on/off) is in conduction. 


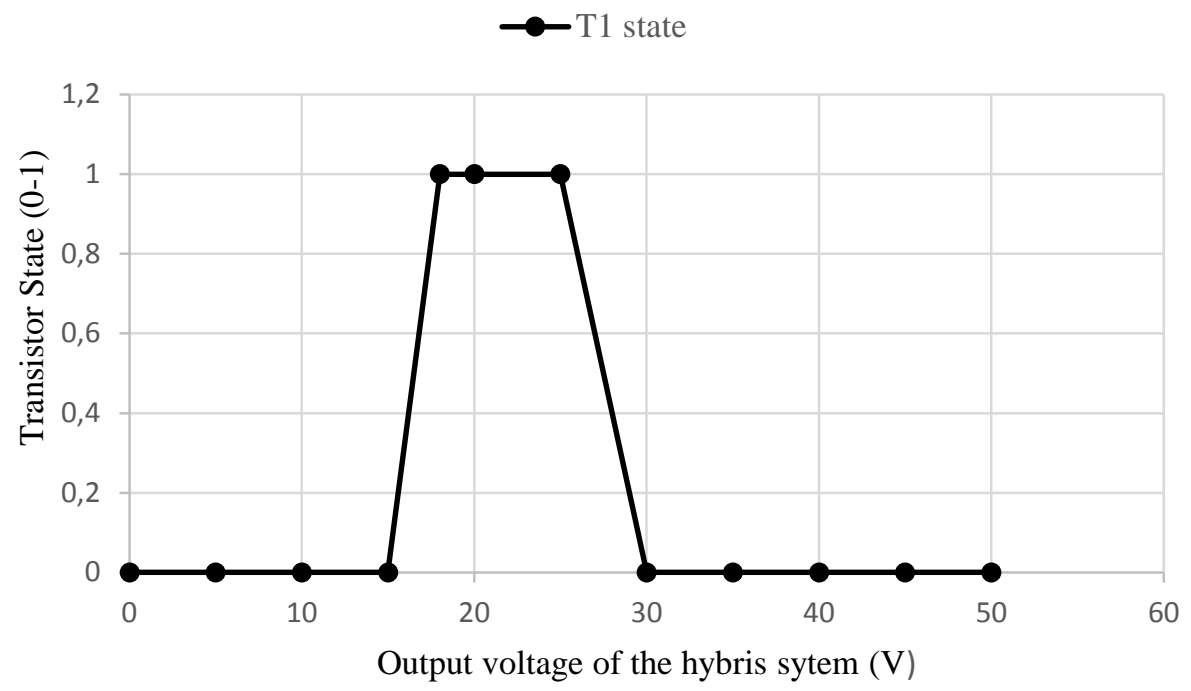

Figure 9.The voltage area where transistors are active(1) and passive (0)

The $\mathrm{T} 1$ transistor controls the RL relay. As the positions of the relay contacts change, the battery will be connected serially to the PV / Wind hybrid circuit to increase the inverter input voltage to the maximum full power voltage. This way, the inverter is prevented from being turned off at the PV/Wind hybrid power stage, which is not very low. Solar irradiation, PV panel output voltage, turbine output voltage, hybrid system output voltage and inverter input-output voltage parameter values and responses of the system are displayed in Table 2 below.

Table 2. The parameter and response of the proposed system

\begin{tabular}{|c|c|c|c|c|c|}
\hline $\begin{array}{c}\text { Irradiation } \\
\left(\mathrm{W} / \mathrm{m}^{2}\right)\end{array}$ & $\begin{array}{c}\text { PV panel } \\
\text { voltage (V) }\end{array}$ & $\begin{array}{c}\text { Turbine } \\
\text { voltage (V) }\end{array}$ & $\begin{array}{c}\text { Hybrid } \\
\text { system } \\
\text { voltage } \\
(\mathrm{V})\end{array}$ & $\begin{array}{c}\text { Input } \\
\text { voltage } \\
\text { micro- } \\
\text { inverter } \\
(\mathrm{V})\end{array}$ & $\begin{array}{c}\text { Output } \\
\text { voltage } \\
\text { micro- } \\
\text { inverter } \\
(\mathrm{V})\end{array}$ \\
\hline 847 & 20.09 & 11 & 20.89 & 33.45 & 220 \\
\hline 847 & 20.09 & 22 & 22 & 34 & 220 \\
\hline- & - & - & 30 & 30 & 220 \\
\hline- & - & - & 40 & 40 & 220 \\
\hline
\end{tabular}

Depending on the solar radiation, Table 2 shows the voltage values obtained from the PV panel, wind turbine output voltage and the inverter input voltage values that are obtained depending on the hybrid system output values. At the same time, Table 2 shows the hybrid system output and inverter input-output voltage values provided from an external DC source by disabling PV and Wind system. As shown in Table 2 and Figure 10, the hybrid system output values varying according to the environmental conditions, are taken into consideration by the proposed system algorithm and the battery is put in the system and taken out successfully. 


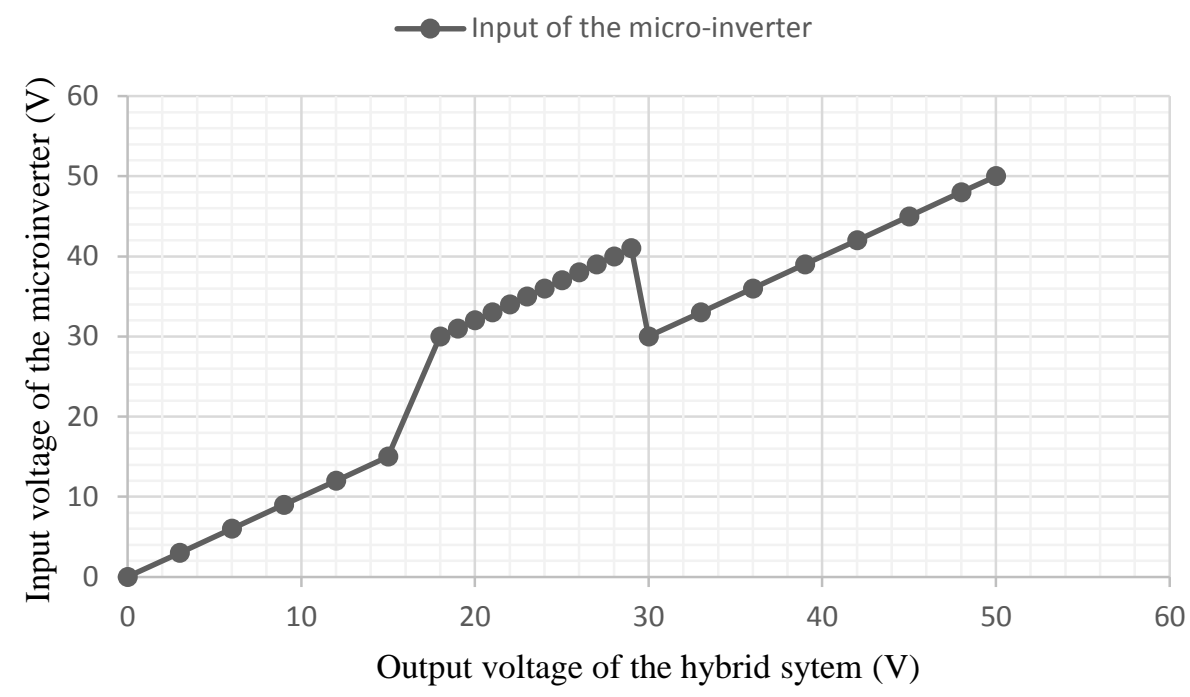

Figure 10. Output voltage of the hybrid system and Input voltage of the micro inverter

\section{Results}

The PV/Wind hybrid energy conversion systems' output powers vary depending on the wind speed temperature and solar radiation.

In the study conducted, the output voltage of the PV / Wind hybrid system was tried to be optimized in consideration of the minimum voltage value that gives the maximum output of a microinverter. To achieve this, the battery on the DC load side is increased slightly with hybrid system power battery support at the very low level, thus maximizing the power supply of the micro-inverter to the grid. Therefore, energy continuity is increased by making use of PV / Wind hybrid system power values which are not very low.

\section{References}

[1] Moradpour, R., Ardi, H., Tavakoli, A., Design and Implementation of a New SEPIC-Based High Step-Up DC/DC Converter for Renewable Energy Applications, IEEE Transactions on Industrial Electronics, 65(2018), 2, 1290-1297.

[2] Afonso, T.L., Marques, A.C., Fuinhas, J.A., Strategies to make renewable energy sources compatible with economic growth, Energy Strategy Reviews, 18(2017), 121-126.

[3] Olabi, A.G., Renewable energy and energy storage systems, Energy, 136(2017), 1-7.

[4] Gosens, J., Natural resource endowment is not a strong driver of wind or PV development, Renewable Energy, 113(2017), 1007-1018.

[5] Gosens, J., Hedenus, F., Sanden, B.A., Faster market growth of wind and PV in late adopters due to global experience build-up, Energy, 131(2017), 267-278.

[6] El-Askary, W.A., Nasef, M.H., AbdEL-hamid, A.A., Gad, H.E., Harvesting wind energy for improving performance of savonius rotor, Journal of Wind Engineering and Industrial Aerodynamics, 139(2015), 8-15. 
[7] Suganthi, S.T., Devaraj, D., Ramar, K., Thilagar, S.H., An Improved Differential Evolution algorithm for congestion management in the presence of wind turbine generators, Renewable and Sustainable Energy Reviews, 81(2018), 635-642.

[8] Maleki, A. (2017), Design and optimization of automous solar-wind-reverse osmosis desalination systems coupling battery and hydrogen energy storage by an improved bee algorithm, Desalination, (2017),In press, http://dx.doi.org/10.1016/j.desal.2017.05.034, 1-14.

[9] Zhang, J., Fang, Z., Shu, C., Zhang, J., Li, C., A rotational piezoelectric energy harvester for efficient wind energy harvesting, Sensors and Actuators A: Physical, 262(2017), 123-129.

[10] Petkovic, D., Pavlovic, N.T., Cojbasic, Z., Wind farm efficiency by adaptive neuro-fuzzy strategy, International Journal of Electrical Power\& Energy Systems, 81(2016), 215-221.

[11] Dileep, G., Singh, S.N., Maximum power point tracking of solar photovoltaic system using modified perturbation and observation method, Renewable and Sustainable Energy Reviews, 50(2015), 109-129.

[12] Louzazni, M., Aroudam, E., Intelligent Control of Photovoltaic Grid-connected Using Fuzzy Logic Based Incremental Conductance, Procedia Technology, 19(2015), 615-622.

[13] Boukezata, B., Gaubert, J.P., Predictive current control in multifunctional grid connected inverter interfaced by PV system, Solar Energy, 139(2016), 130-141.

[14] Gad, H.H., Haikal, A.Y., Hesham, A.A., New design of the PV panel control system using FPGA-based MPSoC, Solar Energy, 146(2017), 243-256.

[15] Farhat, M., Barambones, O., Sbita, L., Efficiency optimization of a DSP-based standalone PV system using a stable single input fuzzy logic controller, Renewable and Sustainable Energy Reviews, 49(2015), 907-920.

[16] Deihimi, A., Zahed, B.K., Iravani, R., An interactive operation management of a micro-grid with multiple distributed generations using multi-objective uniform water cycle algorithm, Energy, 106(2016), 482-509.

[17] Çelik, Ö., Teke, A., Tan, A., Overview of micro-inverters as a challenging technology in photovoltaic applications, Renewable and Sustainable Energy Reviews,(2017), In press, http://dx.doi.org/10.1016/j.rser.2017.10.024.

[18] Bennett, T., Zilouchian A., Messenger R. 2012. Photovoltaic Model and Converter Topology Considerations for MPPT Purposes, Solar Energy, Vol.86, pp. 2029-2040.

[19] Vennel, R., Exceeding the Betz limit with tidal turbines, Renewable Energy, 55(2013), 277-285. 